\title{
Innovative Credit Guarantee Schemes with Equity-for-Guarantee Swaps
}

\author{
Pengcheng Songa, Hai Zhang ${ }^{\mathrm{b}}$, Qin Zhao ${ }^{\mathrm{c}}$, \\ ${ }^{a}$ School of Economics and Finance of Xi'an Jiaotong University,74 Yanta West Road, Xi'an, Shanxi, China \\ ${ }^{b}$ Strathclyde Business School, 199 Cathedral Street, Glasgow, UK \\ ${ }^{c}$ School of Mathematical Sciences, Peking University, No.5 Yiheyuan Road, Beijing, China
}

\begin{abstract}
Small and medium-sized enterprises (SMEs) faces much severer financial constraint compared to large companies and it is more vulnerable to market imperfection. To alleviate SMEs' financial constraints, Public Credit Guarantee Schemes (CGSs) have been introduced and widely used around the world. We first provide a thorough analysis of the effectiveness of the traditional CGSs and then introduce an innovative financing contract, referred to as equity-for-guarantee swap (EGS), with the aim of reducing SMEs' financial constraint in a more effective way. We show that EGS effectively reduces information asymmetry between lenders and SMEs and alleviates SMEs' severe financial constraint. We further investigate the impact of maturity on asset prices under EGS contract and analyse the value-at-risk (VAR) and expected shortfall (ES) of the insurer's risk exposure when participating in the EGS contract. Consistent with pecking order theory, an extension of our model shows that an SME tends to use equity financing first when it faces much severer financial constraint, then the SME issues more debt when it is less financially constrained.
\end{abstract}

Keywords: SMEs, equity-for-guarantee swap, financial constraint, risk management

\section{Introduction}

Small and medium-sized enterprises (SMEs) are often hailed as the backbone of developed and developing economies. It is a consensus that SMEs play a vital role in economic growth, employment creation, boosting foreign trade and poverty alleviation (Ayyagari et al., 2014). Across Organisation for Economic Co-operation and Development (OECD) countries, SMEs account for $99 \%$ of all businesses and between $50 \%$ and $60 \%$ of value added. Almost one person out of three is employed in a micro firm with less than 10 employees and two out of three in an SME, also SMEs are the main drivers of job creation (OECD, 2019). However, its impact on economic and social development can be hampered by difficulties in securing

Email addresses: pengchengsong@xjtu.edu.cn (Pengcheng Song), hai.zhang@strath.ac.uk (Hai Zhang), zhaoqin@pku.edu.cn (Qin Zhao) 
finance, such as access to credit and market-based finance (Cressy, 2002; Stiglitz and Weiss, 1981; Beck and Demirguc-Kunt, 2006; Berger et al., 2005; Canales and Nanda, 2012).

The difficulty in accessing finance, of which is mainly due to existence of information asymmetry between banks and SMEs, is a critical factor constraining the development of SMEs (Wellalage and Fernandez, 2019). Lin and Sun (2006) point out that SMEs are more opaque than large firms and own fewer assets that can be taken as collateral, which makes it more difficult for SMEs to access to bank loans. The most common and greatest creditconstraints for smaller firms include high interest rates, high collateral requirements, and complex procedures in obtaining bank loans (Yoshino and Taghizadeh-Hesary, 2018). SMEs might mitigate this problem by posting collateral or building close relationships with lenders. Nevertheless, such solutions are of little help to firms which lack collateral or credit history (Smith Jr and Warner, 1979; Stulz and Johnson, 1985; Padilla and Pagano, 1998; Coco, 2000; Pozzolo, 2004).

It is imperative to find ways to provide SMEs with stable and sustainable finance. This is a topical issue especially in those regions where SMEs dominate an economy and the constraints have a higher impact (Brown et al., 2009). To alleviate SMEs' financing constraint, Credit Guarantee Schemes (CGSs) have been widely proposed and adopted by banks and governments around the world. A CGS mitigates the credit risk faced by lenders through the absorption of a portion of the lender's losses by a third-party. It is believed that CGSs are effective in improving SMEs' credibility and information disclosure. The World Bank considers Credit Guarantee Schemes (CGSs) as an efficient way to solve the financing problem for SMEs, and releases the principle of public Credit Guarantee Schemes for SMEs in 2015 ${ }^{1}$. More than $79 \%$ of bank loans were insured (World Bank Enterprise Surveys). The amount of guaranteed loans was more than twice the amount of equity financing during the first half of 2013 (Shan and Tang, 2019).

CGSs aim at providing financial support to SMEs suffering from insufficient investment from private financial institutions due to market failures and lack of collateral. In this way, CGSs can enhance the competitiveness of SMEs and finally to increase SME's accessibility to private financing sources. According to Wilcox and Yasuda (2008); Leonello (2018); de Blasio et al. (2018) among others, CGSs have been proven to empirically increase loan supply to SMEs. Respectively, in advanced economies for appraising small business financing, guarantee scheme roughly supplies additional 9\% financing than bank loan and promotes 10\%-13\% probability of getting a loan (Riding and Haines Jr, 2001; Berger et al., 2005; Zecchini and Ventura, 2006). On the other hand, it shows that CGSs are capable to eliminate the financing constraints in theory (Xiang and Yang, 2015).

Despite its popularity, scholars are skeptical about the financial sustainability of CGSs (Vogel and Adams, 1997). The quality of financing instrument determines its sustainability and alleviates the magnitude for SMEs' financing constraint. CGCs normally charge guarantee fees on SMEs which can be detrimental to SMEs' financing if the fees is unaffordable.

\footnotetext{
${ }^{1}$ The World Bank and FIRST Initiative. 2015. Principles for Public Credit Guarantee Schemes for SMEs. Washington, DC: World Bank
} 
In converse, a low guarantee fee would not provide sufficient funding for a sustainable CGSs. Therefore, pricing guarantee fee appropriately is crucial for boosting the CGSs' sustainability.

An insurer faces two typical issues. One is how to effectively reach its policy goals of maintaining a reasonable guarantee capacity for SMEs without damaging its financial health. The other is how to accurately evaluate the risk status of applicants and its guarantee cost. Normally, the guarantee fee (interest rate premium) is set according to the differential between the lending rate for non-guaranteed loans and the rate for guaranteed loans. While for SMEs without much collateral, it might pay higher interest rates to access to bank loans.

The research on whether contributions to the guarantee fund from the public sector may improve or deteriorate the information gathering incentives for Credit Guarantee Scheme has been controversial. On the one hand, public funds raise a potential moral hazard problem. On the other hand, the presence of public funds in a Credit Guarantee Scheme might convey a positive signal to banks about the Credit Guarantee Corporation's capacity, which could attract further external funds that may be used as additional collateral to reduce the expected losses borne by banks should a SME default (Honohan, 2010).

Saito and Tsuruta (2018) suggest that CGSs may increase adverse selection and moral hazard if CGSs cannot distinguish between low- and high-risk borrowers, as the scheme will be more attractive to risky borrowers. Partial credit guarantee schemes have experienced renewed interest from governments keen to promote financial access for SMEs, not least as a response to the credit crunch in advanced economies.

Another disadvantage of most CGSs around the world is that the guarantee fee is fixed throughout the guarantee period without considering the applicant's ever-changing credit status. This practise of no constant monitoring afterwards undoubtedly causes severe moral hazard problems for insurers. In turn, higher default rates and larger amounts of honoring costs will bring CGS to a disaster. Although Kuo et al. (2011) attempt to establish a theoretically sound and practically reasonable model to estimate guarantee fees which reflects an applicant's credit status, there is still a lots remain to be done in the pricing of guarantee fees Therefore, insurers urgently need to pursue a reasonable and applicable method of adjusting guarantee fees according to applicants' risk dynamics throughout the guarantee period.

The operational design apparently influence the cost and effectiveness of differential CGSs (Honohan, 2010). To strength CGS, an innovative instrument called Equity for Guarantee Swap (EGS) has been proposed (Yang and Zhang, 2013; Wang et al., 2015; Liu et al., 2016; Luo et al., 2016; Tang and Yang, 2017). An EGS is a three-party CGS agreement among a bank, a insurer/guarantee company, and an SME, where the SMEr obtains a loan from the bank and, if the SME defaults on the loan, the insurer must pay all the outstanding interest and principal to the bank. In return, the SME transfers part of the ownership as a form of guarantee fee, then the insurer will receive capital gain and dividend from the SMEs for compensation. Inspired by Yang and Zhang (2013), we borrow concepts from the insurance market based on the similarity between guarantee fees and insurance premiums. To be more specific, we blend actuarial pricing theory into the traditional risk-neutral probability of 
default model to investigate insurers' risk exposure signing EGSs contracts. To the best of our knowledge, no previous research has adopted such methodology in credit guarantee pricing.

The pricing framework of our research is closely related to the one in Leland and Toft (1996). Leland (1994) first examines the market value of corporate debt and optimal leverage with closed-form solutions. Further, Leland and Toft (1996) investigate the term structure of the debt and equity with a focus on the analysis of the debt maturity. Goldstein et al. (2001) propose a model based on EBIT and identify another form of optimal capital structure. However, none of the above studies focuses on SMEs financing. In fact, SMEs facing severe financial constraint might not be able to choose the optimal structure. Featuring SMEs financial constraint, varying maturities of contingent claims, and the risk exposure of insurers in an unified dynamic model is another key contribution of this paper.

In this paper, we develop a model of entrepreneurial financing in which credit is rationed because of moral hazard, rather than adverse selection problems. In line with prior work by Holmstrom and Tirole (1997) and Tirole (2001). Our model proves that EGS dominates CGS regarding its effect on alleviating SMEs' severe financial constraint, leading to a Pareto improvement.

Although Yoshino and Taghizadeh-Hesary (2018); Wang et al. (2015) have conducted a thorough analysis on EGS contracts, they ignore the risk exposure for the insurer as they assume that the insurer signs a large number of EGS contracts with various SMEs and thus the idiosyncratic risk would be fully diversified. We argue that it is worthwhile to investigate the risk exposure for the insurer who signs "large" numbers of EGS contracts as no one knows how "large" is sufficient. Therefore, we calculate common risk measures (VaR and ES) of insurer's risk exposure when participating EGS business. Our numerical results illustrate that the insurer breaks even in the long run while makes profit in the short run. We further identify that the main source of insurer's risk exposure comes from SMEs' default risk.

At last, we extend our benchmark model to relax our previous assumption and assume that SMEs could finance project via using both equity and guaranteed loan. Consistent with Myers and Majluf (1984)'s pecking order theory, our model claims that an SME tends to use equity financing first when it faces much severer financial constraint, then the SME issues more debt when it faces less financial constrained.

The rest of our paper is organized as follows. Section 2 develops an unified framework of CGS and EGS pricing which illustrates the innovative EGS outperforms the traditional credit guarantee scheme, leading to a Pareto improvement. Section 3 investigates the impact of varying maturities on asset prices, followed by an indepth analysis of the insurer's risk exposure in Section 4. Section 5 presents numerical results on SMEs optimal structure, asset prices with varying maturities, and risk exposure of insurers as well. Further, an interesting model extension of SMEs financing featuring both equity and debt financing via EGS has been explored in Section 6. Finally, Section 7 concludes and all proofs and technical staffs are gathered in Appendices. 


\section{Benchmark Model: Traditional Credit Guarantee Schemes vs the Innovative Equity-for-Guarantee Swaps}

Following Leland (1994), we assume that the EBIT of a SME, denoted by $\eta$, follows a Brownian motion which is not affected by the capital structure of it. The process of EBIT $\eta_{t}$ satisfies

$$
d \eta=\mu_{\eta} d t+\sigma d Z, \quad \eta_{0} \quad \text { given }
$$

where the growth rate $\mu_{\eta}$ and volatility $\sigma$ are constant, $Z$ is a standard Brownian motion defined on the filtered probability space $\left(\Omega, \mathcal{F},\left\{\mathcal{F}_{t}\right\}_{t \geq 0}, \mathbb{P}\right)$. Define $\frac{d \mathbb{Q}}{d \mathbb{P}}=e^{-\rho \eta_{M} Z_{t}-\frac{1}{2} \rho^{2} \eta_{M}^{2} t}$ with $\eta_{M}$ being the Sharpe ratio of the market, then the stochastic process $\eta$ under risk-neutral measurement is

$$
d \eta=\mu d t+\sigma d Z^{\mathbb{Q}}
$$

where $\mu=\mu_{\eta}-\rho \sigma \eta_{M}$ is the growth rate of the EBIT under risk neutral measure.

Consider a security whose price is denoted by $F\left(\eta_{t}, \vec{g}(t)\right)$, where $\vec{g}(t)=\left(g_{1}(t), g_{2}(t) \ldots g_{i}(t) \ldots\right)$ denotes a vector of cash flow to be paid to the holder and it might be negative. Define the cash flow of the security as $C F\left(\eta_{t}, \vec{g}(t)\right)$. Using Itô formula, the security price $F\left(\eta_{t}, \vec{g}(t)\right)$ satisfies the following ordinary differential equation

$$
\mu F_{\eta}+\frac{\sigma^{2}}{2} F_{\eta \eta}+C F=r F
$$

with a general solution of (3) given by

$$
F\left(\eta_{t}\right)=A_{1} e^{k_{1} \eta_{t}}+A_{2} e^{k_{2} \eta_{t}}+h\left(\eta_{t}, \vec{g}(t)\right),
$$

where

$$
k_{1,2}=\frac{-\mu \pm \sqrt{\mu^{2}+2 r \sigma^{2}}}{\sigma^{2}}
$$

$A_{1}, A_{2}$ and $h\left(\eta_{t}, \vec{g}(t)\right)$ are determined by specific boundary conditions.

\subsection{Traditional credit guarantee schemes}

Due to the high risk of SMEs, it is usually hard for SMEs to access bank loans unless a third party (an insurer for example) agrees to pay the remaining debt should an SME default. Here we consider only a fully protected loan, which means the insurer pays all the residual value of the loan once the SME defaults.

Denote the coupon rate of the loan as $C_{L}$, and the principle as $P$, then a perpetual loan will satisfy $C_{L} / r=P$. In practice, the insurer normally charges an extra premium as the guarantee fee denoted by $C_{G}$, which could be referred as an increase of the coupon rate for the SMEs. Therefore, the total coupon rate $C$ that the SME pays equals to $C_{G}+C_{L}$. For SMEs shareholders, the cash flow is $C F=\left(1-\tau_{f}\right)\left(\eta_{t}-C_{G}-C_{L}\right)$ and the equity price $E\left(\eta_{t}, \eta_{B C}, C_{G}+C_{L}\right)$ satisfies

$$
\mu E_{\eta}+\frac{\sigma^{2}}{2} E_{\eta \eta}+\left(1-\tau_{f}\right)\left(\eta_{t}-C_{G}-C_{L}\right)=r E .
$$


Denote the bankruptcy threshold as $\eta_{B C}$, once the EBIT drops to $\eta_{B C}$ the SMEs will be liquidated. In such case, the market value of the equity will be zero. Then, the boundary conditions of traditional CGS are as follows:

$$
\begin{aligned}
E\left(\eta_{B C}, \eta_{B C}, C_{G}, C_{L}\right) & =0 \\
E\left(\infty, \eta_{B C}, C_{G}, C_{L}\right) & =\left(1-\tau_{f}\right)\left(\frac{\mu+r \eta_{t}-r C_{G}-r C_{L}}{r^{2}}\right)
\end{aligned}
$$

Then the market value of equity can be expressed as:

$E\left(\eta_{t}, \eta_{B C}, C_{G}, C_{L}\right)=\left(1-\tau_{f}\right)\left[\frac{\mu+r \eta_{t}}{r^{2}}-\frac{\mu+r \eta_{B C}}{r^{2}} x_{B}\left(\eta_{t}, \eta_{B C}\right)-\frac{C_{G}+C_{L}}{r}\left(1-x_{B}\left(\eta_{t}, \eta_{B C}\right)\right)\right]$.

As for guarantee fee $G\left(\eta_{t}, \eta_{B C}, C_{G}, C_{L}\right)$, it satisfies:

$$
\mu G_{\eta}+\frac{\sigma^{2}}{2} G_{\eta \eta}+\left(1-\tau_{i}\right) C_{G}=r G .
$$

The boundary conditions for the market value of the guarantee fee is given by

$$
\begin{aligned}
& G\left(\eta_{B C}, \eta_{B C}, C_{G}, C_{L}\right)=0, \\
& G\left(\infty, \eta_{B C}, C_{G}, C_{L}\right)=\left(1-\tau_{i}\right) \frac{C_{G}}{r} .
\end{aligned}
$$

Then the market value of guarantee fee $C_{G}$ can be expressed as:

$$
G\left(\eta_{t}, \eta_{B C}, C_{G}, C_{L}\right)=\left(1-\tau_{i}\right) \frac{C_{G}}{r}\left(1-x_{B}\left(\eta_{t}, \eta_{B C}\right)\right)
$$

As for market value of debt, denoted as $D\left(\eta_{t}, \eta_{B C}, C_{G}, C_{L}, \alpha\right)$, it satisfies:

$$
\mu D_{\eta}+\frac{\sigma^{2}}{2} D_{\eta \eta}+\left(1-\tau_{i}\right) C_{L}=r D
$$

The boundary conditions for the market value of the guarantee fee and the market value of the loan $D\left(\eta_{t}, \eta_{B C}, C_{L}, \alpha\right)$ can be expressed as

$$
\begin{aligned}
D\left(\eta_{B C}, \eta_{B C}, C_{G}, C_{L}, \alpha\right) & =\left(1-\tau_{i}\right)(1-\alpha) \frac{\mu+r \eta_{B C}}{r^{2}} x_{B}\left(\eta_{t}, \eta_{B C}\right), \\
D\left(\infty, \eta_{B C}, C_{G}, C_{L}, \alpha\right) & =\left(1-\tau_{i}\right) \frac{C_{L}}{r} .
\end{aligned}
$$

The market value of loan is given by

$$
D\left(\eta_{t}, \eta_{B C}, C_{G}, C_{L}, \alpha\right)=\left(1-\tau_{i}\right)\left[\frac{C_{L}}{r}\left(1-x_{B}\left(\eta_{t}, \eta_{B C}\right)\right)+(1-\alpha) \frac{\mu+r \eta_{B C}}{r^{2}} x_{B}\left(\eta_{t}, \eta_{B C}\right)\right]
$$

Furthermore, the guarantee fee $C_{L}$ and coupon rate $C_{G}$ satisfies

$$
D\left(\eta_{t}, \eta_{B C}, C_{G}, C_{L}, \alpha\right)+G\left(\eta_{t}, \eta_{B C}, C_{G}, C_{L}\right)=\left(1-\tau_{i}\right) \frac{C_{L}}{r} .
$$

Then $C_{G}$ and $C_{L}$ satisfies the following equation:

$$
C_{G}=\frac{\left[r C_{L}-(1-\alpha)\left(\mu+r \eta_{B C}\right)\right]}{r\left(1-\tau_{i}\right)} \frac{x_{B}\left(\eta_{t}, \eta_{B C}\right)}{1-x_{B}\left(\eta_{t}, \eta_{B C}\right)} .
$$




\subsection{Equity-for-Guarantee Swap Pricing}

We hereafter summarise key results from Yang and Zhang (2013). Under Equity-forGuarantee swap, the guarantee fee is paid to the insurer by a certain portion of SMEs equity. Different from the traditional CGS, the cash flow that bank receives under EGS is $\left(1-\tau_{i}\right) C$. Thus, the ODE that $E\left(\eta_{t}, \eta_{B}, C\right)$ that satisfies is given by

$$
\mu E_{\eta}+\frac{\sigma^{2}}{2} E_{\eta \eta}+\left(1-\tau_{f}\right)\left(\eta_{t}-C\right)=r E
$$

with boundary conditions as follows which are similar to (6):

$$
\begin{aligned}
E\left(\eta_{B}, \eta_{B}, C\right) & =0 \\
E\left(\infty, \eta_{B}, C\right) & =\left(1-\tau_{f}\right)\left(\frac{\mu+r \eta_{t}-r C}{r^{2}}\right) .
\end{aligned}
$$

According to (16), we can derive the market value of the equity as

$$
E\left(\eta_{t}, \eta_{B}, C\right)=\left(1-\tau_{f}\right)\left[\frac{\mu+r \eta_{t}}{r^{2}}-\frac{\mu+r \eta_{B}}{r^{2}} x_{B}\left(\eta_{t}, \eta_{B}\right)-\frac{C}{r}\left(1-x_{B}\left(\eta_{t}, \eta_{B}\right)\right)\right]
$$

Similarly, the time-invariant value of the debt with a coupon rate $\mathrm{C}$, denoted by $D\left(\eta_{t}, \eta_{B}, C, \alpha\right)$ satisfies

$$
\mu D_{\eta}+\frac{\sigma_{\eta}^{2}}{2} D_{\eta \eta}+\left(1-\tau_{i}\right) C=r D
$$

with boundary conditions defined as follows

$$
\begin{aligned}
D\left(\eta_{B}, \eta_{B}, C, \alpha\right) & =\left(1-\tau_{i}\right)(1-\alpha) \frac{\mu+r \eta_{B}}{r^{2}} x_{B}\left(\eta_{t}, \eta_{B}\right) \\
D\left(\infty, \eta_{B C}, C, \alpha\right) & =\left(1-\tau_{i}\right) \frac{C}{r} .
\end{aligned}
$$

In the same way, the market value of the debt is given as follows

$$
D\left(\eta_{t}, \eta_{B}, C, \alpha\right)=\left(1-\tau_{i}\right)\left[\frac{C}{r}\left(1-x_{B}\left(\eta_{t}, \eta_{B}\right)\right)+(1-\alpha) \frac{\mu+r \eta_{B}}{r^{2}} x_{B}\left(\eta_{t}, \eta_{B}\right)\right] .
$$

And the fair market value of the guarantee should be

$$
G\left(\eta_{t}, \eta_{B}, C\right)=\frac{\left[r C-(1-\alpha)\left(\mu+r \eta_{B}\right)\right]}{r^{2}} x_{B}\left(\eta_{t}, \eta_{B}\right)
$$

The insurer will take part of the SME's equity for compensation. The shares $\beta$ requested by the insurer is solved by

$$
\beta=\frac{G\left(\eta_{t}, \eta_{B}, C\right)}{E\left(\eta_{t}, \eta_{B}, C\right)} .
$$




\subsection{Optimal Capital Structure}

Now we turn into the optimal capital structure problem for SMEs under both the traditional CGS and EGS-CGS settings. We first look at the optimal capital structure under EGS-CGS setting.

It's trivial to solve the optimal bankruptcy threshold by maximizing the market value of the equity according to the first-order condition

$$
\frac{\partial E\left(\eta_{t}, \eta_{B}, C\right)}{\partial \eta_{B}}=0
$$

The optimal bankruptcy threshold is given by

$$
\eta_{B}^{*}=C-\frac{\mu}{r}+\frac{1}{k_{2}} .
$$

The SMEs owner chooses the optimal debt level $C^{*}$ to maximise the total value with the optimal bankruptcy threshold. The objective function is defined as follows

$$
C^{*}=\underset{C}{\arg \max }\left\{E\left(\eta_{t}, \eta_{B}^{*}, C\right)+D\left(\eta_{t}, \eta_{B}^{*}, C, \alpha\right)\right\}
$$

Solving the above equation, the optimal coupon rate $C^{*}$ should satisfy

$$
\left(\tau_{f}-\tau_{i}\right)+\left(\alpha k_{2} C^{*}-\tau_{f}\right) e^{k_{2} \eta_{t}-k_{2} C^{*}+k_{2} \mu / r-1}=0 .
$$

Under the framework of a traditional CGS, we define the bankruptcy threshold as $\eta_{B C}$ , the optimal bankruptcy threshold $\eta_{B C}^{*}$, and the total coupon rate $C^{\prime}$. The new optimal bankruptcy threshold should still satisfy (25) but with a new coupon rate $C^{\prime}=C_{G}+C_{L}$, and its expression is given by

$$
\eta_{B C}^{\prime *}=C_{G}^{\prime}+C_{L}^{\prime}-\frac{\mu}{r}+\frac{1}{k_{2}}
$$

Similar to the previous case with EGS, the optimal coupon rate and guarantee premium are solved by the following equation

$$
C_{G}^{* *}, C_{L}^{*}=\underset{C_{G}^{\prime}, C_{L}^{\prime}}{\arg \max }\left\{E\left(\eta_{t}, \eta_{B C}^{*}, C_{G}^{\prime}+C_{L}^{\prime}\right)+D\left(\eta_{t}, \eta_{B C}^{\prime *}, C_{L}^{\prime}, \alpha\right)\right\},
$$

subject to (15). We refer $C_{L}^{\prime}$ and $C$ as the effective debt level under traditional CGS and the innovative EGS respectively. Summarising the previous results, we have the following two propositions

Proposition 1. The optimal effective debt level of EGS-CGS is higher than that of CGS, which means EGS-CGS relieves more financial pressure than CGS. When the EGS-CGS and CGS take the same effective debt level, the probability of default of the SME is lower with the innovative EGS-CGS. The proposed innovative EGS-CGS is a Pareto improvement of the traditional $C G S$.

The proof is provided in the Appendix A. 


\section{Asset Prices with Varying Maturities}

Suryani (2020) point out that one of the problem of CGS is that it's difficult to manage the risk. As the EGS-CGS dominates the traditional CGS, here we consider only the risk management of EGS-CGS contract. More specifically, We investigate the dynamic of the assets' value and the impact of maturity on the values of SME's equity, guarantee, and bank loan.

Firstly, the bankruptcy probability will be derived according to Shreve (2004), and it will be used to derive the value of equity, EBIT and loan. Denote $t_{B}$ as the first passage time of EBIT process to $\eta_{B}$, the bankruptcy probability of a SME defaulting before $t$ can be expressed as

$$
\operatorname{Pr}\left(t_{B} \leq t\right)=\operatorname{Pr}\left(m_{t} \leq \eta_{B}\right)=\Phi\left(\frac{-\eta_{0}+\eta_{B}-\mu t}{\sigma \sqrt{t}}\right)+e^{-2\left(\eta_{0}-\eta_{B}\right) \mu / \sigma^{2}} \Phi\left(\frac{-\eta_{0}+\eta_{B}+\mu t}{\sigma \sqrt{t}}\right),
$$

where $\Phi(\cdot)$ is the cumulative distribution function of standard normal distribution, and $m_{t}=\min _{s \in[0, t]}\left\{\eta_{s}\right\}$. Here $t$ should satisfy $t<\infty$. The $\operatorname{Pr}\left(t_{B} \leq t\right)$ is strictly monotonically decreasing for $\eta_{t}$ and $\mu$, and strictly monotonically increasing for $\eta_{B}$ and $t$.

It is a trivial to calculate the probability that a SME never goes bankruptcy as follows

$$
\operatorname{Pr}\left(t_{B}=\infty\right)=1-e^{-2\left(\eta_{0}-\eta_{B}\right) \mu / \sigma^{2}} .
$$

One should notice that the the probability has a flaw at $\infty$. If we consider the probability under the condition that the SME goes bankruptcy in a finite time, i.e. $\operatorname{Pr}\left(t_{B} \mid t_{B}<\infty\right)$, then the bankruptcy time $t_{B}$ follows the inverse Gaussian distribution

$$
\operatorname{Pr}\left(t_{B} \mid t_{B}<\infty\right)=e^{2\left(\eta_{0}-\eta_{B}\right) \mu / \sigma^{2}} \Phi\left(\frac{-\eta_{0}+\eta_{B}-\mu t}{\sigma \sqrt{t}}\right)+\Phi\left(\frac{-\eta_{0}+\eta_{B}+\mu t}{\sigma \sqrt{t}}\right) .
$$

\subsection{Pricing equity with varying maturities}

According to (30), the joint distribution of $\eta_{t}$ and $m_{t}$ is derived as follows

$$
\operatorname{Pr}\left(\eta_{t} \geq x, m_{t} \geq \eta_{B}\right)=\Phi\left(\frac{-x+\eta_{0}+\mu t}{\sigma \sqrt{t}}\right)-e^{2 \mu\left(\eta_{B}-\eta_{0}\right) \sigma^{-2}} \Phi\left(\frac{2 \eta_{B}-\eta_{0}-x+\mu t}{\sigma \sqrt{t}}\right) .
$$

Then, the probability density function of $\eta_{t}$, conditioning on $m_{t} \geq \eta_{B}$, can be derived by calculating the partial derivative of $\eta_{t}$ :

$$
f\left(\eta_{t}, m_{t} \geq \eta_{B}\right)=\frac{1}{\sigma \sqrt{t}} \phi\left(\frac{-\eta_{t}+\eta_{B}}{\sigma \sqrt{t}}+g_{1}\right)-\frac{1}{\sigma \sqrt{t}} e^{-2\left(\eta_{0}-\eta_{B}\right) \mu / \sigma^{2}} \phi\left(\frac{-\eta_{t}+\eta_{B}}{\sigma \sqrt{t}}+g_{2}\right),
$$

where $g_{1,2}=\frac{ \pm\left(\eta_{0}-\eta_{B}\right)+\mu t}{\sigma \sqrt{t}}$.

The expectation of EBIT at time $t$ where $t<\infty$ is given by

$E\left[\eta_{t}, m_{t} \geq \eta_{B}\right]=\frac{\sigma \sqrt{t}}{\sqrt{2 \pi}} e^{-\frac{g_{1}^{2}}{2}}+\left(\mu t+\eta_{0}\right) \Phi\left(g_{1}\right)-e^{-2\left(\eta_{0}-\eta_{B}\right) \mu / \sigma^{2}}\left(\frac{\sigma \sqrt{t}}{\sqrt{2 \pi}} e^{-\frac{g_{2}^{2}}{2}}+\left(\mu t+2 \eta_{B}-\eta_{0}\right) \Phi\left(g_{2}\right)\right)$. 
It is quite straightforward that we should discount the EBIT with different maturities. However, according to (35), it is difficult to derive the expected return of the equity directly by integrating the present value of (35) from 0 to t. According to Equation (18), the expect return of future cash flow is only determined by EBIT $\eta_{t}$. Therefore, according to the law of total expectation, the expectation of the capital return in future is given by

$$
\left.E\left[E\left[\eta_{t}, \eta_{B}, C\right] \mid \eta_{t}\right]\right]=\int_{\eta_{B}}^{\infty} E\left[\eta_{t}, \eta_{B}, C\right] f\left(\eta_{t}, m_{t} \geq \eta_{B}\right) d \eta_{t}
$$

where $f\left(\eta_{t}, m_{t} \geq \eta_{B}\right)$ is the probability density function defined in Equation (34).

Consider Equation (18), we only need to calculate the expectation of $x_{B}\left(\eta_{t}, \eta_{B}\right)$. Now we derive an important equation in our paper as follows

$$
E\left[x_{B}\left(\eta_{t}, \eta_{B}\right)\right]=\Phi\left(j_{1}\right) e^{k_{2}\left(\eta_{0}-\eta_{B}\right)+r t}+\Phi\left(j_{2}\right) e^{k_{1}\left(\eta_{0}-\eta_{B}\right)+r t},
$$

where

$$
j_{1,2}=\frac{\mp\left(\eta_{B}-\eta_{0}\right)-t \sqrt{\mu^{2}+2 r \sigma^{2}}}{\sigma \sqrt{t}} .
$$

The Equation (18) and (21) indicate the coefficient before the positive characteristic root $A_{1}$ must be 0 due to the second boundary condition. However, it still plays an important role when considering varying maturities. When t comes to zero, the value of (37) approaches to $p_{B}\left(\eta_{t}, \eta_{B}\right)$

$$
\lim _{t \rightarrow 0}\left[\Phi\left(j_{1}\right) e^{k_{2}\left(\eta_{0}-\eta_{B}\right)+r t}+\Phi\left(j_{2}\right) e^{k_{1}\left(\eta_{0}-\eta_{B}\right)+r t}\right]=e^{k_{2}\left(\eta_{0}-\eta_{B}\right)}
$$

When $t$ goes infinity, we have

$$
\lim _{t \rightarrow+\infty}\left[\Phi\left(j_{1}\right) e^{k_{2}\left(\eta_{0}-\eta_{B}\right)+r t}+\Phi\left(j_{2}\right) e^{k_{1}\left(\eta_{0}-\eta_{B}\right)+r t}\right]=0 .
$$

Revisiting (36), we can break the integral into three parts

$$
\begin{gathered}
E\left[E\left(\eta_{t}, \eta_{B}, C\right) \mid \eta_{t}\right]=z_{1}+z_{2}+z_{3}, \\
z_{1}=\int_{\eta_{B}}^{\infty}\left(1-\tau_{f}\right)\left(\frac{\mu-r C}{r^{2}}\right) f\left(\eta_{t}, m_{t} \geq \eta_{B}\right) d \eta_{t} \\
z_{2}=\int_{\eta_{B}}^{\infty}\left(1-\tau_{f}\right) \frac{\eta_{t}}{r} f\left(\eta_{t}, m_{t} \geq \eta_{B}\right) d \eta_{t}, \\
z_{3}=\int_{\eta_{B}}^{\infty}\left(1-\tau_{f}\right) \frac{C-\mu / r-\eta_{B}}{r} x_{B}\left(\eta_{t}, \eta_{B}\right) f\left(\eta_{t}, m_{t} \geq \eta_{B}\right) d \eta_{t} .
\end{gathered}
$$

According to Equation (33),(35), and (37), the present value of $E\left[E\left(\eta_{t}, \eta_{B}, C\right)\right]$ is given as

$$
S(t)=E\left(\eta_{0}, \eta_{B}, C\right)-E\left[E\left(\eta_{t}, \eta_{B}, C\right) \mid \eta_{t}\right] e^{-r t}
$$




\subsection{The value of the insurer's payment with varying maturities}

According to (32), the cumulative probability distribution function of $t_{B}$ is given buy with a flaw. However, it doesn't affect the present value of future payment of the bank. Thus, we have

$$
\lim _{t \rightarrow+\infty} L_{t} e^{-r t}=0
$$

The probability density function is given by solving the partial derivatives ${ }^{2}$ of $t_{B}$ as follows

$$
f\left(t_{B}\right)=\frac{\eta_{0}-\eta_{B}}{\sigma} t_{B}^{-3 / 2} \frac{1}{\sqrt{2 \pi}} e^{-\frac{\left(\eta_{B}-\eta_{0}-\mu t_{B}\right)^{2}}{2 \sigma^{2} t_{B}}} .
$$

We first consider such an asset which receives one unit payment When the firm goes bankruptcy before $t$ and nothing otherwise. The expectation of the present value of one unit payment, by integrating from 0 to $t$, is

$$
E\left[L_{0}, t\right]=\int_{0}^{t} e^{-r s} f(s) d s=\Phi\left(d_{1}\right) e^{h_{1}}+\Phi\left(d_{2}\right) e^{h_{2}} .
$$

where

$$
\begin{gathered}
d_{1,2}=\frac{-\eta_{0}+\eta_{B} \mp \sqrt{\mu^{2}+2 r \sigma^{2}} t}{\sigma \sqrt{t}}, \\
h_{1,2}=\frac{\left(-\eta_{0}+\eta_{B}\right)\left(-\mu \mp \sqrt{\mu^{2}+2 r \sigma^{2}}\right)}{\sigma^{2}} .
\end{gathered}
$$

Assume that the SME goes bankruptcy at time $t_{B}$, then the insurer pays

$$
D_{g}\left(\eta_{B}, \eta_{B}, C\right)=\frac{\left[r C-(1-\alpha)\left(\mu+r \eta_{B}\right)\right]}{r^{2}} .
$$

And the present value of the payment is given by

$$
L_{0}\left(t_{B}\right)=\frac{\left[r C-(1-\alpha)\left(\mu+r \eta_{B}\right)\right]}{r^{2}} e^{-r t_{B}} .
$$

According to Equation (43), we have

$$
E\left[L_{0}, t_{B}\right]=\frac{\left[r C-(1-\alpha)\left(\mu+r \eta_{B}\right)\right]}{r^{2}}\left(\Phi\left(d_{1}\right) e^{h_{2}}+\Phi\left(d_{2}\right) e^{h_{1}}\right) .
$$

As the present value of the payment is strictly monotonically decreasing for $t$, then $t_{B}=\operatorname{Pr}^{-1}(a)$ represents the bankruptcy time corresponding to the quantile a.

\footnotetext{
${ }^{2}$ This probability density function is informal, but it does not affect our conclusion.
} 


\section{Risk Exposure of the Insurer}

Theoretically, the idiosyncratic risk faced by an insurer could be diversified by investing in a significantly large number of EGS contracts. Although the Law of Large numbers holds when the insurer signs EGS contracts with a very large quantity of SMEs, it seems impossible for an insurer to invest in such many EGS contracts. In fact, there might be not many companies in the market and if the number of SMEs defaults during finite time is larger than that expected, the excess part of loss of the insurer will exist permanently. Therefore, it is worthwhile to investigate the risk exposure of the insurer.

Here we apply two familiar risk measurements for the insurer signing EGS contracts, i.e. value at risk(VaR) and expected shortfall (ES, also called CVaR), which are given by

$$
\begin{gathered}
V a R_{a}=\inf _{s}\{\operatorname{Pr}(L \leq s) \geq a\}, \\
C V a R_{a}=E\left(L \mid L \geq V a R_{a}\right),
\end{gathered}
$$

where a is the quantile of the distribution of the random variable L, i.e. the loss of a portfolio.

More specifically, the VaR of the random variable can be expressed as

$$
\operatorname{VaR}_{a}\left[L_{0}\right]=e^{-r P r^{-1}(a)}\left(\frac{C}{r}-(1-\alpha) \frac{\mu+r \eta_{B}}{r^{2}}\right),
$$

and the expected shortfall of the random variable can be expressed as

$$
E S_{a}\left[L_{0}\right]=\frac{1}{1-\alpha} \int_{0}^{V a R_{a}} e^{-r P r^{-1}(a)}\left(\frac{C}{r}-(1-\alpha) \frac{\mu+r \eta_{B}}{r^{2}}\right) f(t) d t .
$$

We consider that an insurer signs EGS contracts with $\mathrm{N}$ companies. $\mathrm{N}$ is a not small number and not too large such that the central limit theorem could be applied to the analysis the aggregate loss. We further assume that the SMEs are homogenous and have the same characteristics, the random variables of the SMEs' bankruptcy probability are independent and identically distributed, i.i.d.

As a result, at a stopping time $t<\infty$, the numbers of bankrupted firms $N_{B}$ follows a binomial distribution as follows

$$
\operatorname{Pr}\left(N_{B}=n_{B}\right)=\left(\begin{array}{c}
N \\
n_{B}
\end{array}\right) p^{n_{B}}(1-p)^{N-n_{B}}
$$

where $p=\operatorname{Pr}\left(t_{B} \leq t\right)$ is the bankruptcy probability according to Equation (30). When $\mathrm{N}$ is large, using the central limit theorem, the distribution of number of firms that goes bankruptcy follows a Gaussian distribution $\operatorname{Normal}(N p, N p(1-p))$,

$$
\operatorname{Pr}\left(N_{B} \leq n_{B}\right)=\Phi\left(\frac{n_{B}-N p}{\sqrt{N p(1-p)}}\right)
$$


Thus, the present value of the random variable before $t$ is

$$
L_{0}[t]= \begin{cases}0 & t_{B}>t, \\ e^{-r t_{B}}\left(\frac{C}{r}-(1-\alpha) \frac{\mu+r \eta_{B}}{r^{2}}\right) & t_{B} \leq t .\end{cases}
$$

We rewrite the expectation of $L_{0}$ considering the risk free interest rate $\mathrm{r}$ as follows

$$
\operatorname{var}\left[L_{0}, t_{B}, r\right]=E\left[L_{0}^{2}, t_{B}, r\right]-\left(E\left[L_{0}, t_{B}, r\right]\right)^{2}=E\left[L_{0}, t_{B}, 2 r\right]-\left(E\left[L_{0}, t_{B}, r\right]\right)^{2} .
$$

According to the central limit theorem, the distribution of the present value of aggregate loss before $t_{B}$, denoted by $L_{0}^{a}$, follows a Gaussian distribution $N \operatorname{ormal}\left(N E\left[L_{0}, t_{B}, r\right], N \operatorname{var}\left[L_{0}, t_{B}, r\right]\right)$

$$
\operatorname{Pr}\left(L_{0}^{a}<l\right)=\Phi\left(\frac{l-N * E\left[L_{0}, t_{B}, r\right]}{\sqrt{N * \operatorname{var}\left[L_{0}, t_{B}, r\right]}}\right) .
$$

Finally, VaR and ES of the present value of aggregate payment are given by

$$
\begin{gathered}
\operatorname{VaR}_{a}\left[L_{0}^{a}\right]=N * E\left[L_{0}, t_{B}, r\right]+\Phi^{-1}(a) \sqrt{N * \operatorname{var}\left[L_{0}, t_{B}, r\right]}, \\
E S_{a}\left[L_{0}^{a}\right]=N * E\left[L_{0}, t_{B}, r\right]+E S_{a}(N \operatorname{ormal}(0,1)) \sqrt{N * \operatorname{var}\left[L_{0}, t_{B}, r\right]} .
\end{gathered}
$$

Given a fixed $\eta_{0}$, the ES and VaR are both time-variant risk measurements, which provides flexibility regarding the analysis of risk exposures of the insurer.

As for the whole EGS contract, We consider the difference between the equity return and compensation payment of an insurer which is defined as follows

$$
\begin{aligned}
C G(t) & =\int_{i=0}^{t}\left(1-\tau_{f}\right) \beta\left(\eta_{s}-C\right) e^{-r s} 1_{\left\{m_{s} \geq \eta_{B}\right\}} d s-L e^{-r s} 1_{\left\{m_{s}=\eta_{B}\right\}} \\
& =\int_{i=0}^{t}\left(1-\tau_{f}\right) \beta \eta_{s} e^{-r s} 1_{\left\{m_{s} \geq \eta_{B}\right\}} d s-\left[\left(L-\frac{C}{r}\right) e^{-r s}+\frac{C}{r}\right] 1_{\left\{m_{s}=\eta_{B}\right\}}
\end{aligned}
$$

First we consider the case of a standard Brownian motion where an SME never goes bankruptcy. If the process of P\&L follows a standard Brownian motion $z_{t}$, then CG becomes

$$
C G(t)=\int_{0}^{t} e^{-r s} z_{s} d s
$$

and the variance of $\mathrm{CG}$ can be expressed as follows

$$
\operatorname{var}(C G(t))=\int_{0}^{t}\left(\int_{0}^{s} e^{-r(s+\tau)} \sigma^{2} \tau d \tau+\int_{s}^{t} e^{-r(s+\tau)} \sigma^{2} s d \tau\right) d s,
$$

and

$$
\begin{aligned}
\operatorname{var}(C G(t)) & =\int_{0}^{t}\left(\int_{0}^{s} e^{-r(s+\tau)} \sigma^{2} \tau d \tau+\int_{s}^{t} e^{-r(s+\tau)} \sigma^{2} s d \tau\right) d s, \\
& =\frac{t}{r^{2}} e^{-2 r t}+\frac{1}{2 r^{3}}-\frac{2}{r^{3}} e^{-r t}+\frac{3}{2 r^{3}} e^{-2 r t} .
\end{aligned}
$$


When interest rate $\mathrm{r}$ approaches zero, we have $\lim _{r \rightarrow 0} C G(t)=\frac{1}{3} \sigma^{2} t^{3}$.

Similarly, denote $\left[\left(L-\frac{C}{r}\right) e^{-r t}+\frac{C}{r}\right] 1_{\left\{m_{t}=\eta_{B}\right\}}$ as $L(t)$, we can derive the variance of capital gain in a general case as

$$
\begin{aligned}
\operatorname{var}(C G(t))= & \left(1-\tau_{f}\right)^{2} \beta^{2} \int_{0}^{t} \int_{0}^{t} e^{-r(s+\tau)} \operatorname{cov}\left(\eta_{s} 1_{\left\{m_{s} \geq \eta_{B}\right\}}, \eta_{\tau} 1_{\left\{m_{\tau} \geq \eta_{B}\right\}}\right) d \tau d s \\
& -2\left(1-\tau_{f}\right) \beta \int_{0}^{t} e^{-r s} \operatorname{cov}\left(L(t), \eta_{s} 1_{\left\{m_{s} \geq \eta_{B}\right\}}\right) d s+\operatorname{var}(L(t)) .
\end{aligned}
$$

The covariance of $\eta_{s} 1_{\left\{m_{s} \geq \eta_{B}\right\}}, \eta_{\tau} 1_{\left\{m_{\tau} \geq \eta_{B}\right\}}$ can be expressed as follows

$$
\begin{aligned}
\operatorname{cov}\left(\eta_{s} 1_{\left\{m_{s} \geq \eta_{B}\right\}}, \eta_{\tau} 1_{\left\{m_{\tau} \geq \eta_{B}\right\}}\right)= & E\left[E\left[\eta_{\tau} 1_{\left\{m_{\tau} \geq \eta_{B}\right\}} \eta_{s} 1_{\left\{m_{s} \geq \eta_{B}\right\}} \mid \eta_{\tau} 1_{\left\{m_{\tau} \geq \eta_{B}\right\}}\right]\right] \\
& -E\left[\eta_{\tau} 1_{\left\{m_{\tau} \geq \eta_{B}\right\}}\right] E\left[\eta_{s} 1_{\left\{m_{s} \geq \eta_{B}\right\}}\right] .
\end{aligned}
$$

The VaR and ES of an insurer who has signed a given N EGS contracts can be calculated using numerical methods.

\section{Numerical Analysis}

We have derived optimal capital structure of an SME under both the CGS case and the innovative EGS case in Section 2, asset pricies with varying maturities in Section 3, and insurers' risk exposure in Section 4. In this section, we provide numerical results to develop more economic intuition on the innovative EGSs contract. Baseline parameters are chosen according to Yang and Zhang (2013) among others. Table 1 summarises the parameter values used in our baseline case.

\subsection{Optimal capital structure between the traditional CGS and the innovative EGS}

Overall, the proposed EGS dominates the traditional CGS regarding its effect on alleviating SMEs' severe financial constraint. The optimal coupon rate for EGS and CGS are presented in Figure 1a which shows the "effective" coupon level is much higher under the innovative EGS than that under the traditional CGS. As expected, SMEs borrow less loan when the EBIT volatility is higher, whixh can be explained by an increased default risk in such case.

Consistent with Figure 1a, the optimal capital structure illustrated in Figure 1b indicates SMEs under EGS optimally choose higher leverage compared with the traditional CGS case. More specifically, the optimal leverage for an SME borrowing loan via EGS is over $90 \%$ while the figure for an SME under CGS is just over $50 \%$.

Figure 2 shows the relationship between the SME's guarantee cost and its project quality. In most cases, an SME will to give up below $10 \%$ of its equity as guarantee fees for debt financing. The guarantee cost rises to over $35 \%$ for SMEs with poor quality projects, i.e. lower expected growth rate and high risk. 
Table 1: Summary of key parameters in baseline case

\begin{tabular}{lcc}
\hline Parameter & Symbol & Value \\
\hline EBIT value of the firm at time 0 & $\eta_{0}$ & 10 \\
Bankruptcy threshold & $\eta_{B}$ & 4 \\
Expected growth rate of EBIT under real probability measure $\mathbb{P}$ & $\mu$ & 0.25 \\
Expected growth rate of EBIT under risk neutral measure $\mathbb{Q}$ & $\mu_{\eta}$ & 0.01 \\
Risk free interest rate & $r$ & 0.05 \\
Volatility of EBIT & $\sigma$ & 0.6 \\
Sharp ratio of the market & $\eta_{M}$ & 0.4 \\
Correlation coefficient between the SME and the market & $\rho$ & 1 \\
Number of insured SMEs & $N$ & 1000 \\
Bankruptcy cost ratio & $\alpha$ & $50 \%$ \\
Effective tax rate & $\tau_{f}$ & 0.48 \\
Continuous coupon rate & $C$ & \\
Time of bankruptcy & $t_{B}$ & \\
Payment to the debtor when $t_{B}=t$ & $L_{t}$ & \\
Maturity of the loan & $M$ & \\
\hline
\end{tabular}

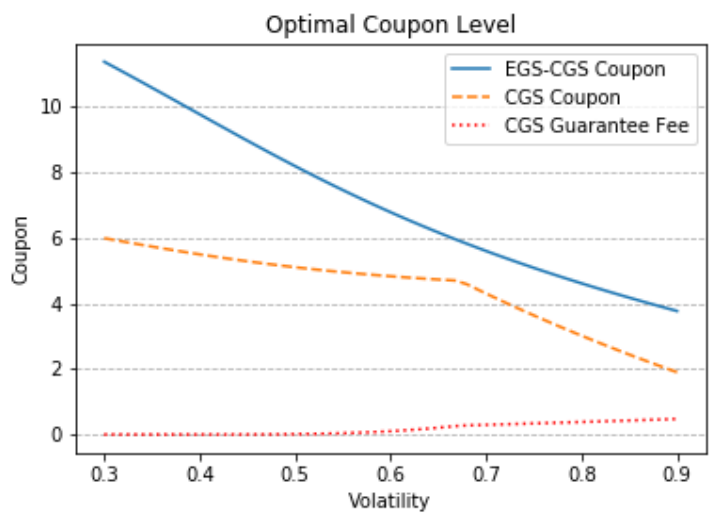

(a) Optimal coupon level

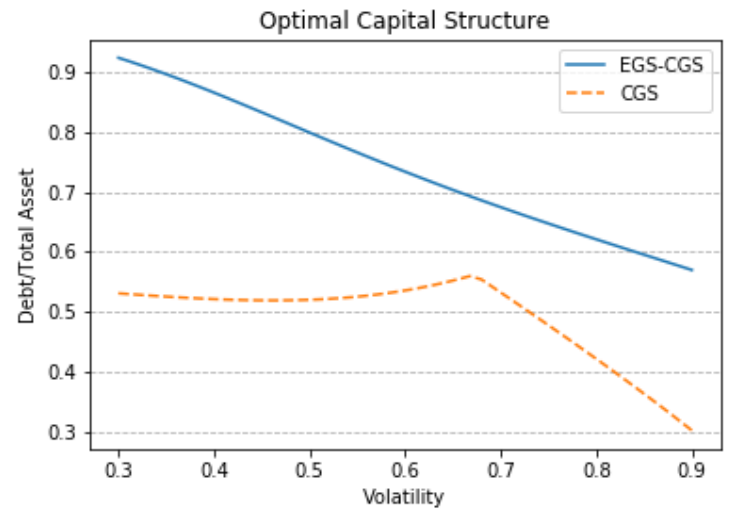

(b) Optimal capital structure

Figure 1: Comparison of optimal capital structures between CGS and EGS 


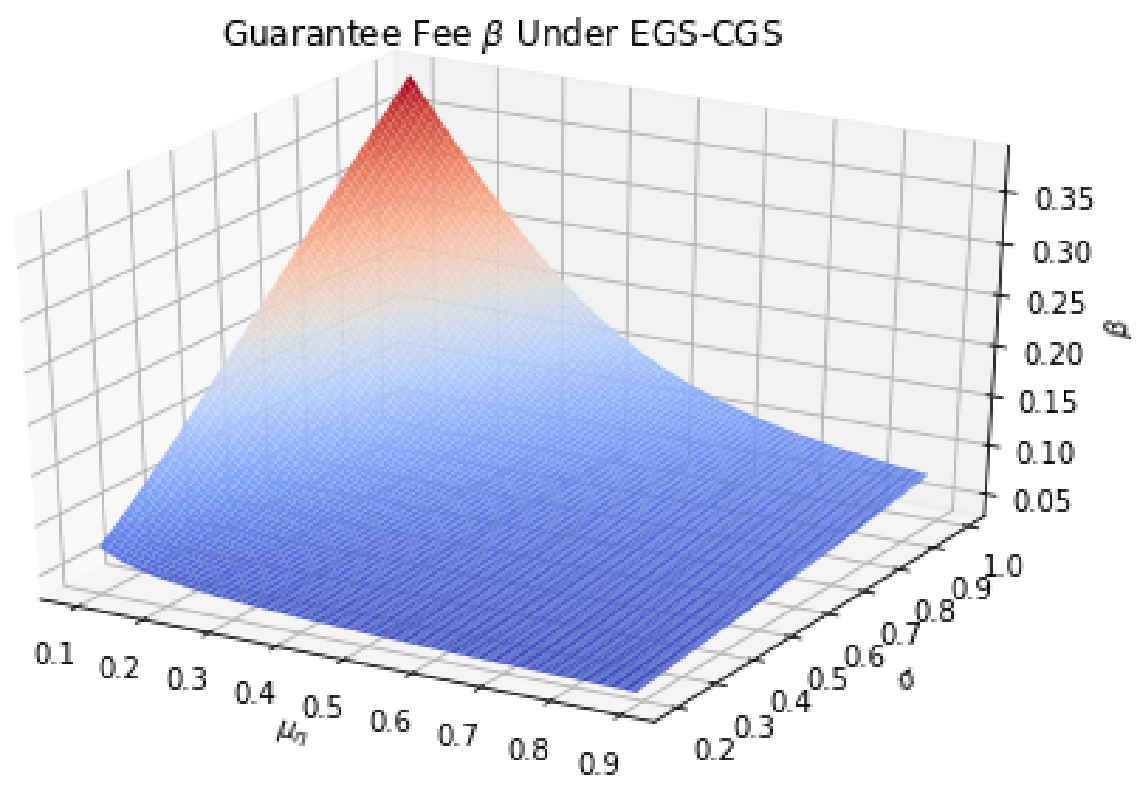

Figure 2: EBIT quality (i.e. the expected growth rate and the volatility) and its impact on guarantee cost

\subsection{The impact of maturity on asset prices}

Figure 3 presents the present value of an insurer's payment to the bank with varying maturities should an SME default. As expected, the insurer's payment to the bank is larger for a longer maturity debt as this would increase an SME's bankruptcy probability. On the contrary, the insurer's payment would be smaller for an SME with a higher expected growth rate or a lower volatility project, as the default risk in both cases are much lower. 


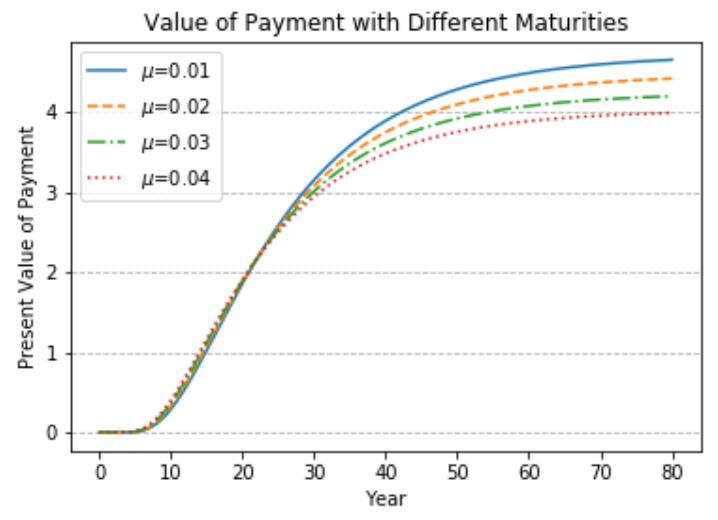

(a)

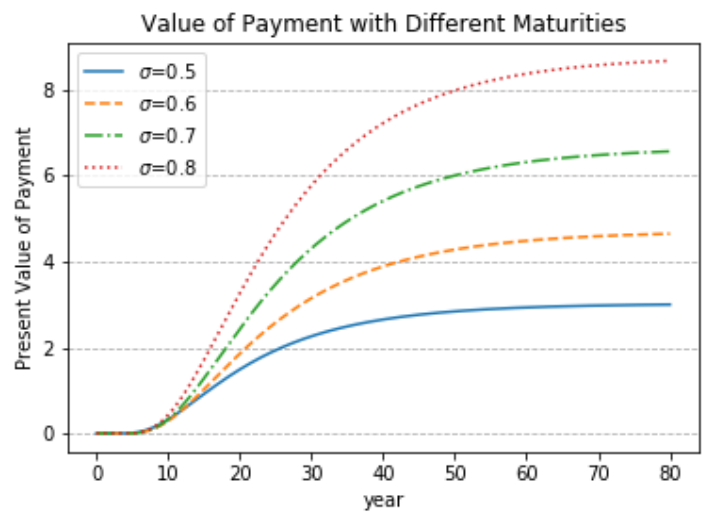

(b)

Figure 3: The impact of varying maturities on payment with different levels of growth rate and volatility

Figure 4 presents the value of equity for different maturities with different levels of growth rate and volatility. As expected, the longer the SME survives, the higher the value of its equity. Against the intuition, the equity value would be lower for a higher expected growth rate and a lower volatility. This is mainly because that the SMEs in such cases issues more debt.

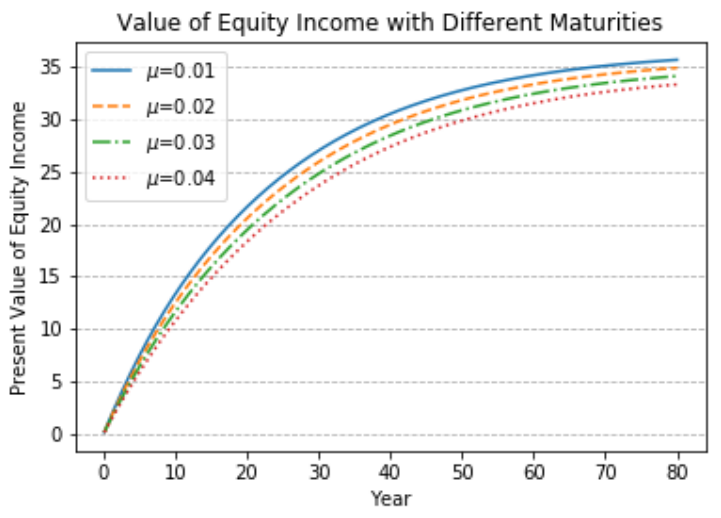

(a)

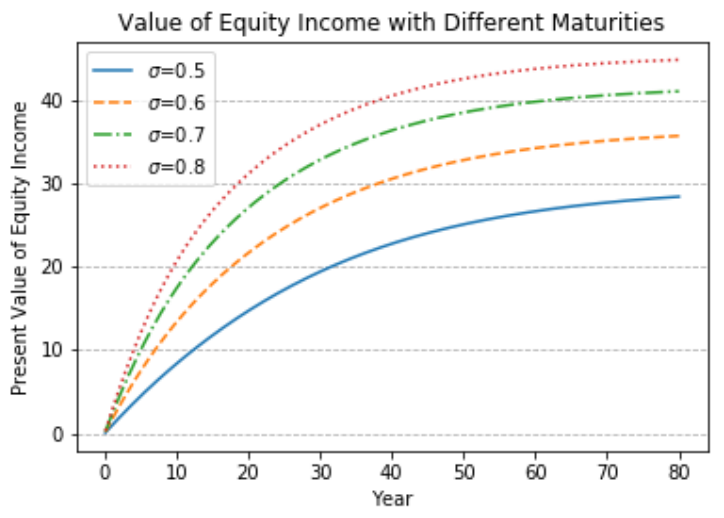

(b)

Figure 4: The impact of varying maturities on equity value with different levels of growth rate and volatility

\subsection{Insurers' risk exposure}

We assume the insurer signs $N=1000$ ESG contracts in our numerical experiment. The expected number of defaulted SMEs is presented in Figure 5 and the expected payment in Figure 6 . 


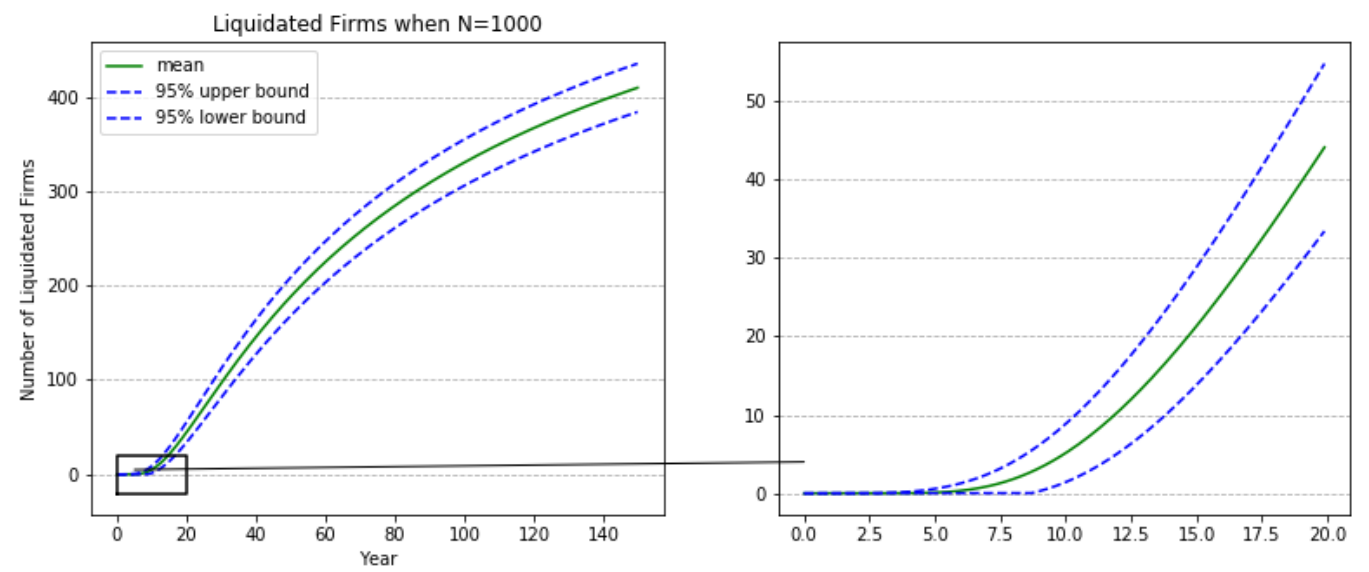

Figure 5: The number of defaulted firms.

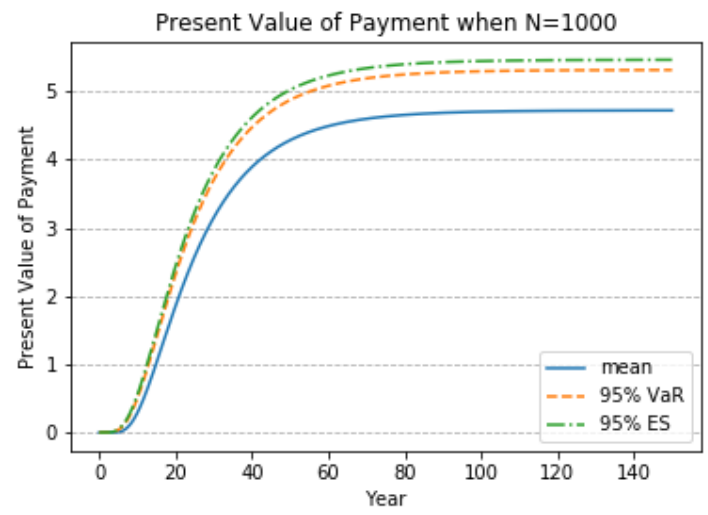

Figure 6: The insurer's expected payment should SMEs default.

In the short run case with the maturity $t \leq 10$ years, only a few of companies get liquidated, thus the insurer's payment to the bank is smaller. However, over $40 \%$ (more than 400) SMEs default in the long-term which results a higher expected payment by the insurer.

When combining the equity income gained from EGS contract, the insurer breaks even in the long run as its capital gain approaches to zero as shown in Figure 7a. While in the short run, due to few SMEs defaults, the insurer has positive profit on average with its VaR and ES both being positive as well. 


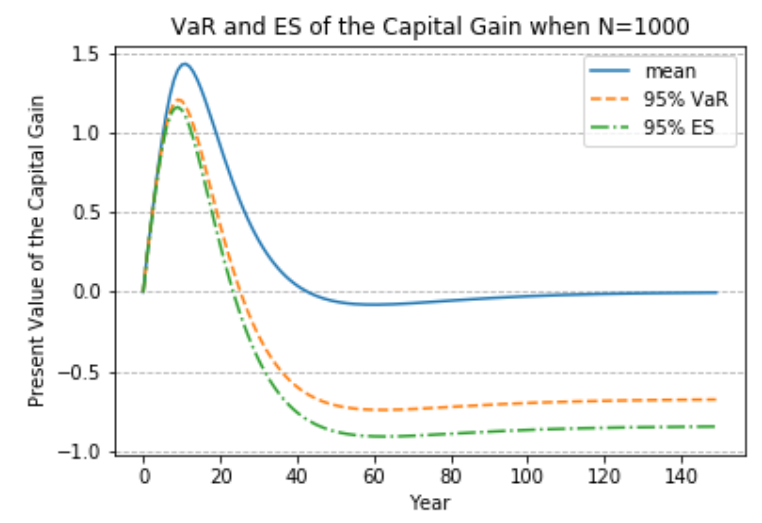

(a)

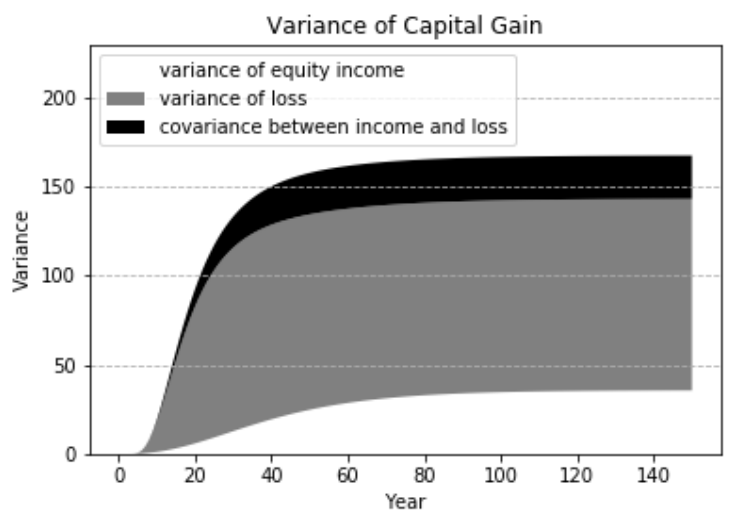

(b)

Figure 7: The insurer's capital gain (CG) and its variance composition

We further investigate the key sources of the risk of capital gain in Figure 7b. More specifically, we find that the largest portion of the variance of capital gain comes from the variance of payment, which indicates the main resource of the risk associated to the EGS contract is from the default risk of firms.

\section{Model Extension: Debt or Equity?}

Consider the model mentioned in Section 2, what is the impact of an additional equity investment on the firm? In this section we attempt to address an SME's optimal financing choice, i.e. debt or equity?

\subsection{SMEs' optimal financing structure}

Here we consider an interesting extension of our basic model by introducing equity financing option to SMEs. In the benchmark model, we assume SMEs finances its capital via guaranteed bank loan only. Here, we relax our previous assumption and assume that SMEs could finance project via using both equity and guaranteed loan. One advantage of introducing equity financing is that it boosts the growth rate of SMEs.

Assume that $\eta_{t}$ is continuous, the coupon rate $\mathrm{C}$ is determined by the loan level $\mathrm{L}$, and the volatility $\sigma$ is constant, the following condition should be satisfied

$$
E\left(\eta_{t}, C(L), \mu\right)+I=E\left(\eta_{t}, C(L), \mu^{\prime}\right),
$$

which is consistent with that the additional equity investment boosts the growth rate $\mu^{\prime}$.

From the perspective of the SME, it plans to make equity financing I and debt financing $\mathrm{L}$ subject to a exogenous financing constraint A to maxmise the firm value. We take $\eta_{t}$ as constant, then denote $E\left(\eta_{t}, C(L), \mu\right)$ as $E(C(L), \mu)$. Equation (60) means that an additional equity investment will promote the growth rate of the EBIT of the firm without affecting its volatility. After receiving the equity investment, the firm will choose a new optimal bankruptcy threshold, $\eta_{B}^{*}=C(L)-\mu^{\prime} / r-1 / k_{2}$, to maximise its market value. 
For the reason that $E(C(L), \mu)$ is strictly monotonous increasing for $\mu$, there exists a unique $\mu^{\prime}$ that satisfies (51) and is determined by $L$ and $I$. Then we can rewrite the market value of equity under this condition as

$$
E(C(L), \mu(I, L))=E(I, L)
$$

Now we can define the objective function of the SMEs as follows ${ }^{3}$

$$
V(I, L)=\operatorname{Pr}\left(t_{B}=\infty\right)\left[E(I, L)+\left(1-\tau_{i}\right) L-D_{g}(I, L)-I\right] .
$$

The optimization problem for the firm can be expressed as

$$
\begin{gathered}
\max _{I, L} V(I, L), \\
\text { s.t.I } \geq 0, \\
L \geq 0, \\
I+L \leq A .
\end{gathered}
$$

We should notice that there is no closed-form solution for Equation (62), thus, a numerical method has been employed to find the optimal capital structure of the SMEs.

\subsection{Simulation results}

As no closed-form solution obtained for SMEs' optimal financing structure, we here provide a comprehensive numerical analysis investigating the key determinants of SMEs' optimal capital structure.

Firstly, we investigate the effect of financial constraint (also referred as budget constraint) on SMEs' optimal financing decisions. As indicated in Figure 8, firms generally tend to issue more debt, a higher leverage, when they have decent budget and face no or little financial constraint (i.e. the budget constraint $A \geq 250$ ). On the contrary, an SME issues more equity when it has limited budget and faces severe financial constraint. Our numerical results are consistent with the pecking order theory first proposed by Myers and Majluf (1984). To be more specific, when the financial budget is tight, $A=50$, of which 40 comes from equity issue, only 10 from debt issue, as indicated in Figure 9b.

\footnotetext{
${ }^{3}$ According to $L=C / r$, we can conclude directly that $\frac{\partial v(0, r C)}{\partial C}$ equals to the left side of $(27)$.
} 


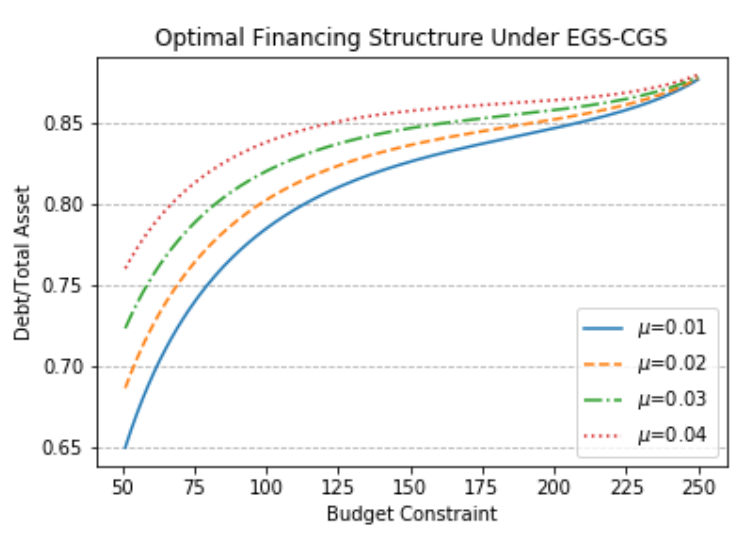

(a)

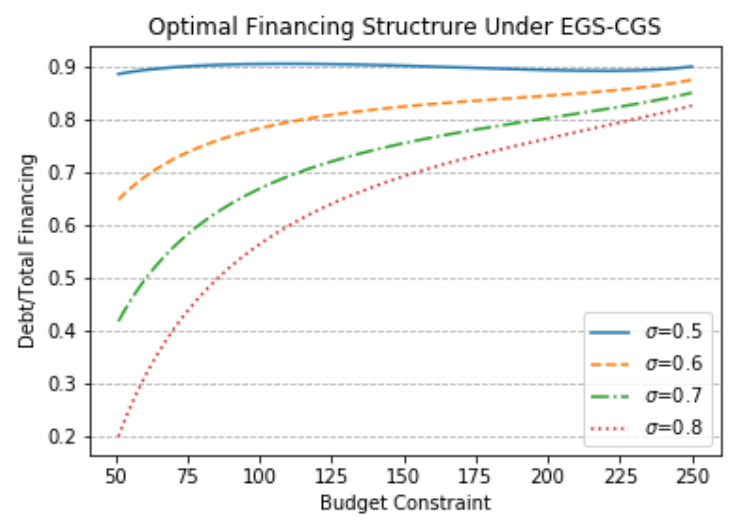

(b)

Figure 8: optimal financing structure with different levels of growth rate and volatility

Secondly, we focus on the effect of project quality on optimal capital structure decisions. Figure 8a shows that SMEs with higher growth potentials, on average, choose higher leverage ratios, the effect of which is stronger when financial constraint is much more severe. For example, an SME with $\mu=0.7$ chooses its optimal financing leverage of around $76 \%$, while only $65 \%$ for an SME with $\mu=0.4$.

Lastly, we analyse the impact of volatility on the optimal capital structure decisions. As it can be seen from Figure 8b and 9a, the higher the volatility or the riskier of the project is, the smaller the optimal financing leverage ratio. This is straightforward as a higher EBIT volatility leads to a higher default risk, which further reduces SMEs' incentive of issuing debt due to the greater bankruptcy cost. Moreover, such detrimental effect on debt issuance is much stronger when SMEs face much more severe financial constraint.

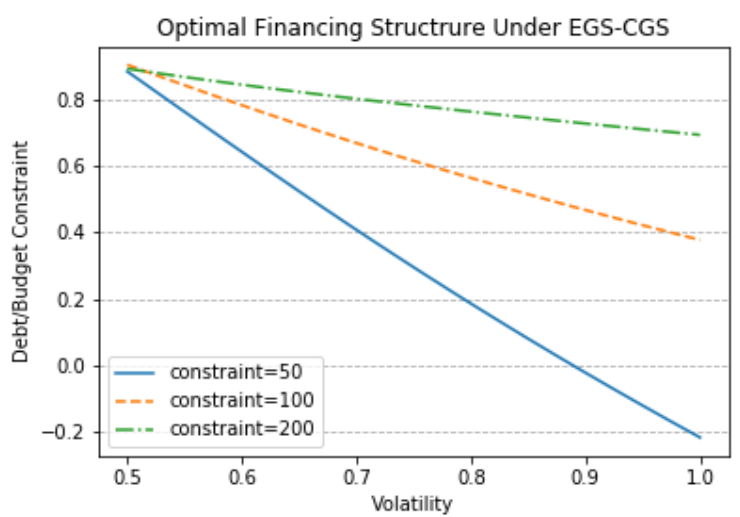

(a)

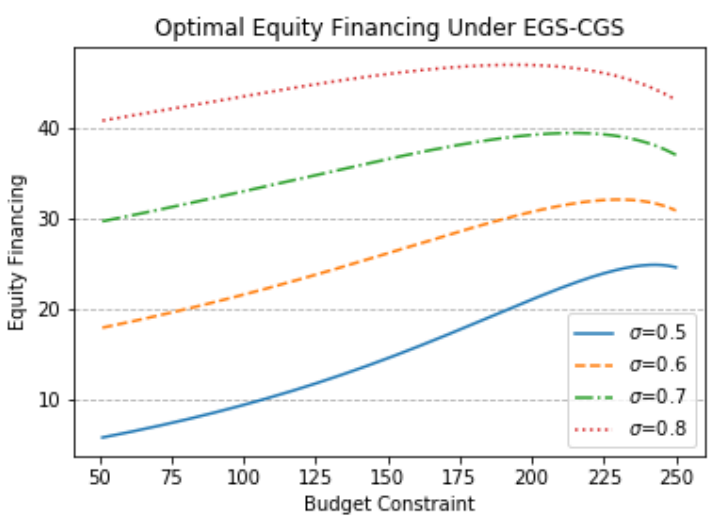

(b)

Figure 9: Optimal financing structure with different levels of budget constraint and volatility 


\section{Conclusion}

Small and medium-sized enterprises (SMEs) plays a crucial role in the global economy not just for employment creation and being the engines of economic growth, but also being considered as a forceful tool of poverty alleviation in most developing and undeveloped countries. However, SMEs face much severer financial constraint compared to large companies and they are more vulnerable to market imperfection. In this paper, we propose an innovative credit guarantee scheme with EGS to alleviate such severe financial constraint faced by SMEs.

We first develop an unified dynamic SMEs financing model which provides a thorough analysis and comparison of the traditional CGS and the innovative EGS. Our model proves that EGS dominates CGS regarding its effect on alleviating SMEs' severe financial constraint, leading to a Pareto improvement.

Moreover, we calculate common risk measures (VaR and ES) of insurer's risk exposure when participating EGS business. Our numerical results illustrate that the insurer breaks even in the long run while makes profit in the short run. We further identify that the main source of insurer's risk exposure comes from SMEs' default risk.

Finally, we extend our benchmark model to relax our previous assumption and assume that SMEs could finance project via using both equity and guaranteed loan. Consistent with the pecking order theory, an SME tends to use equity financing first when it faces much severer financial constraint, then the SME issues more debt when it faces less financial constrained.

\section{Appendices}

\section{Appendix A The proof of Proposition 1}

According to Section 2, we can conclude that $C^{*}$ is the only extreme point for Equation (27), then the extreme point satisfies the first order condition of (29). Further, $C^{*}$ satisfies

$$
\frac{d E\left(\eta_{t}, \eta_{B}^{*}, C\right)}{d C}+\frac{d D\left(\eta_{t}, \eta_{B}^{*}, C, \alpha\right)}{d C}=0,
$$

and

$$
\begin{cases}\frac{d E\left(\eta_{t}, \eta_{B}^{*}, C\right)}{d C}+\frac{d D\left(\eta_{t}, \eta_{B}^{*}, C, \alpha\right)}{d C}>0 & C<C^{*}, \\ \frac{d E\left(\eta_{t}, \eta_{B}^{*}, C\right)}{d C}+\frac{d D\left(\eta_{t}, \eta_{B}^{*}, C, \alpha\right)}{d C}<0 & C>C^{*} .\end{cases}
$$

If we substitute $C^{\prime}=C_{G}^{\prime}+C_{L}^{\prime}$, the first order condition for Equation (29) can be rewritten as

$$
\frac{d E\left(\eta_{t}, \eta_{B C}^{*}, C^{\prime}\right)}{d C^{\prime}}+\frac{d D\left(\eta_{t}, \eta_{B C}^{* *}, C^{\prime}, \alpha\right)}{d C^{\prime}}\left(1-\frac{d C_{G}^{\prime}}{d C^{\prime}}\right)=0 .
$$

It is obvious that $\frac{d C_{G}^{\prime}}{d C^{\prime}}>0$ holds when $C_{G}^{\prime}, C_{L}^{\prime}$ satisfies (15). 
According to Equation (21), we know $\frac{d D\left(\eta_{t}, \eta_{B}, C, \alpha\right)}{d C}>0$, then we can conclude that, in order to satisfy the first order condition of traditional credit guarantee scheme, the optimal coupon rate $C^{*}$ must be smaller than $C^{*}$ using a EGS. Now we have proved Proposition 1.

\section{Appendix B The impact of maturity on asset prices}

B.1 Pricing a unit payment with different maturities

$$
\begin{aligned}
E\left[L_{0}, t\right] & =E\left[e^{-r t_{B}}, t_{B} \leq t\right] \\
& =E\left[e^{-r t_{B}} \mathbb{1}_{\left[t_{B} \leq t\right]}\right] \\
& =\int_{0}^{t} e^{-r s} f(s) d s \\
& =\int_{0}^{t} \frac{\eta_{0}-\eta_{B}}{\sigma} s^{-3 / 2} \frac{1}{\sqrt{2 \pi}} e^{-\frac{\left(\eta_{B}-\eta_{0}-\mu s\right)^{2}}{2 \sigma^{2} s}} e^{-r s} d s \\
& =\int_{0}^{t} \frac{\eta_{0}-\eta_{B}}{\sigma} s^{-3 / 2} \frac{1}{\sqrt{2 \pi}} e^{-\frac{\left(-\sqrt{\mu^{2}+2 r \sigma^{2}} s+\left(\eta_{B}-\eta_{0}\right)\right)^{2}}{2 \sigma^{2} s}} e^{-\frac{\sqrt{\mu^{2}+2 r \sigma^{2}}\left(\eta_{B}-\eta_{0}\right)-\mu\left(\eta_{B}-\eta_{0}\right)}{\sigma^{2}}} d s \\
& =\frac{\eta_{0}-\eta_{B}}{\sigma} \frac{\sigma}{\eta_{0}-\eta_{B}} e^{-\frac{\sqrt{\mu^{2}+2 r \sigma^{2}}\left(\eta_{B}-\eta_{0}\right)-\mu\left(\eta_{B}-\eta_{0}\right)}{\sigma^{2}}}\left[\Phi\left(\frac{\left(\eta_{B}-\eta_{0}\right)-\sqrt{\mu^{2}+2 r \sigma^{2}} t}{\sigma \sqrt{t}}\right)\right. \\
& \left.+e^{\frac{2 \sqrt{\mu^{2}+2 r \sigma^{2}}\left(\eta_{B}-\eta_{0}\right)}{\sigma^{2}}} \Phi\left(\frac{\left(\eta_{B}-\eta_{0}\right)+\sqrt{\mu^{2}+2 r \sigma^{2}} t}{\sigma \sqrt{t}}\right)\right] .
\end{aligned}
$$

B.2 The value of EBIT with different maturities

$$
E\left[\eta_{t}, m_{t} \geq \eta_{B}\right]=\int_{\eta_{B}}^{\infty} \eta_{t} f\left(\eta_{t}, m_{t} \geq \eta_{B}\right) d \eta_{t} .
$$

The probability density function is given as follows

$$
\begin{gathered}
f\left(\eta_{t}=x, m_{t} \geq \eta_{B}\right)=\frac{1}{\sigma \sqrt{t}} \phi\left(\frac{-x+\eta_{0}+\mu t}{\sigma \sqrt{t}}\right)-\frac{e^{2 \mu\left(\eta_{B}-\eta_{0}\right) \sigma^{-2}}}{\sigma \sqrt{t}} \phi\left(\frac{2 \eta_{B}-\eta_{0}-x+\mu t}{\sigma \sqrt{t}}\right) . \\
E\left[\eta_{t}, m_{t} \geq \eta_{B}\right]=\int_{\eta_{B}}^{\infty} \frac{x}{\sigma \sqrt{t}} \phi\left(\frac{-x+\eta_{0}+\mu t}{\sigma \sqrt{t}}\right)-\frac{e^{2 \mu\left(\eta_{B}-\eta_{0}\right) \sigma^{-2} x}}{\sigma \sqrt{t}} \phi\left(\frac{2 \eta_{B}-\eta_{0}-x+\mu t}{\sigma \sqrt{t}}\right) d x \triangleq J_{1}+J_{2}
\end{gathered}
$$

Firstly, we solve $J_{1}$

$$
J_{1}=\int_{\eta_{B}}^{\infty} \frac{x}{\sigma \sqrt{t}} \phi\left(\frac{-x+\eta_{0}+\mu t}{\sigma \sqrt{t}}\right) d x .
$$


Define $\hat{x}=\frac{-x+\eta_{0}+\mu t}{\sigma \sqrt{t}}$. Then

$$
\begin{aligned}
J_{1} & =\int_{-\infty}^{\frac{-\eta_{B}+\eta_{0}+\mu t}{\sigma \sqrt{t}}}\left(\frac{\eta_{0}+\mu t}{\sqrt{2 \pi}} e^{-\frac{1}{2} \hat{x}^{2}}-\frac{\sigma \sqrt{t}}{\sqrt{2 \pi}} \hat{x} e^{-\frac{1}{2} \hat{x}^{2}}\right) d \hat{x} \\
& =\left(\eta_{0}+\mu t\right) \Phi\left(\frac{-\eta_{B}+\eta_{0}+\mu t}{\sigma \sqrt{t}}\right)+\frac{\sigma \sqrt{t}}{\sqrt{2 \pi}} e^{-\frac{1}{2}\left(\frac{-\eta_{B}+\eta_{0}+\mu t}{\sigma \sqrt{t}}\right)^{2}} .
\end{aligned}
$$

Use the same method to define $\tilde{x}=\frac{2 \eta_{B}-\eta_{0}-x+\mu t}{\sigma \sqrt{s}}$, we have

$$
\begin{aligned}
J_{2} & =-\int_{\eta_{B}}^{\infty} \frac{e^{2 \mu\left(\eta_{B}-\eta_{0}\right) \sigma^{-2}} x}{\sigma \sqrt{t}} \phi\left(\frac{2 \eta_{B}-\eta_{0}-x+\mu t}{\sigma \sqrt{t}}\right) d x \\
& =-e^{2 \mu\left(\eta_{B}-\eta_{0}\right) \sigma^{-2}} \int_{-\infty}^{\frac{\eta_{B}-\eta_{0}+\mu t}{\sigma \sqrt{t}}}\left(-\frac{\sigma \sqrt{t} \tilde{x}}{\sqrt{2 \pi}} e^{-\frac{1}{2} \tilde{x}^{2}}+\frac{2 \eta_{B}-\eta_{0}+\mu t}{\sqrt{2 \pi}} e^{-\frac{1}{2} \tilde{x}^{2}}\right) d \tilde{x} \\
& =-e^{2 \mu\left(\eta_{B}-\eta_{0}\right) \sigma^{-2}}\left[\frac{\sigma \sqrt{t}}{\sqrt{2 \pi}} e^{-\frac{1}{2}\left(\frac{\eta_{B}-\eta_{0}+\mu t}{\sigma \sqrt{t}}\right)^{2}}+\left(2 \eta_{B}-\eta_{0}+\mu t\right) \Phi\left(\frac{\eta_{B}-\eta_{0}+\mu t}{\sigma \sqrt{t}}\right)\right] .
\end{aligned}
$$

\section{Appendix C Expected value of $p_{B}\left(\eta_{t}, \eta_{B}\right)$}

The expected value of $p_{B}\left(\eta_{t}, \eta_{B}\right)$ can be expressed as

$$
E\left[e^{k_{2}\left(\eta_{t}-\eta_{B}\right)}\right]=\int_{\eta_{B}}^{\infty} e^{k_{2}\left(\eta_{t}-\eta_{B}\right)} f\left(\eta_{t}, m_{t} \geq \eta_{B}\right) d \eta_{t} .
$$

Similar to the previous approach adopted in Appendix B, we divide the right side of the above equation into two parts $O_{1}$ and $O_{2}$

$$
\begin{gathered}
O_{1}=\int_{\eta_{B}}^{\infty} \frac{1}{\sigma \sqrt{t}} \phi\left(\frac{-x+\eta_{0}+\mu t}{\sigma \sqrt{t}}\right) e^{k_{2}\left(\eta_{t}-\eta_{B}\right)} d x \\
O_{2}=-\int_{\eta_{B}}^{\infty} \frac{e^{2 \mu\left(\eta_{B}-\eta_{0}\right) \sigma^{-2}}}{\sigma \sqrt{t}} \phi\left(\frac{2 \eta_{B}-\eta_{0}-x+\mu t}{\sigma \sqrt{t}}\right) e^{k_{2}\left(\eta_{t}-\eta_{B}\right)} d x .
\end{gathered}
$$

Define $\hat{x}=\frac{x-\eta_{0}+\sqrt{\mu^{2}+2 r \sigma^{2}} t}{\sigma \sqrt{t}}$, then

$$
O_{1}=\int_{\frac{\eta_{B}-\eta_{0}+t \sqrt{\mu^{2}+2 r \sigma^{2}}}{\sigma \sqrt{t}}}^{\infty} \phi(x) e^{k_{2}\left(\eta_{0}-\eta_{B}\right)+r t} d x .
$$

In the same way, define $\tilde{x}=\frac{2 \eta_{B}-\eta_{0}-x+\mu t}{\sigma \sqrt{t}}$, then

$$
O_{2}=\int_{\frac{-\left(\eta_{B}-\eta_{0}\right)+t \sqrt{\mu^{2}+2 r \sigma^{2}}}{\sigma \sqrt{t}}}^{\infty} \phi(x) e^{k_{1}\left(\eta_{0}-\eta_{B}\right)+r t} d x .
$$




\section{C.1 Second order expectation of EBIT}

It is vital for an insurer to know its risk exposure signing EGSs contracts. To calculate the VaR of the capital gain of such contract during finite time, we derive first the second-order expectation of the EBIT at time $t$ is as follows

$$
E\left[\eta_{t}^{2}, m_{t} \geq \eta_{B}\right]=\int_{-\infty}^{\eta_{B}} \eta_{t}^{2} f\left(\eta_{t}, m_{t} \geq \eta_{B}\right) d \eta_{t}
$$

According to Appendix B, it is trivial to use the same transformation to integrate Equation (C.6),

$$
E\left[\eta_{t}^{2}, m_{t} \geq \eta_{B}\right]=Q_{1}+Q_{2}
$$

where

$$
\begin{gathered}
Q_{1}=\left[\sigma^{2} t+\left(\eta_{0}+\mu t\right)^{2}\right] \Phi\left(g_{1}\right)+\frac{\sigma \sqrt{t}\left(\eta_{0}+\eta_{B}+\mu t\right)}{\sqrt{2 \pi}} e^{-\frac{1}{2} g_{1}^{2}} \\
Q_{2}=-e^{2 \mu\left(\eta_{B}-\eta_{0}\right) \sigma^{-2}}\left\{\left[\sigma^{2} t+\left(2 \eta_{B}-\eta_{0}+\mu t\right)^{2}\right] \Phi\left(g_{2}\right)+\frac{\sigma \sqrt{t}\left(3 \eta_{B}-\eta_{0}+\mu t\right)}{\sqrt{2 \pi}} e^{-\frac{1}{2} g_{2}^{2}}\right\} .
\end{gathered}
$$

C.2 Second order expectation of equity value

The second order expectation of $E\left(\eta_{t}, \eta_{B}, C\right)$ is given as follows

$$
\int_{\eta_{B}}^{+\infty} E^{2}\left(\eta_{t}, \eta_{B}, C\right) f\left(\eta_{t}, m_{t} \geq \eta_{B}\right) d \eta_{t}=\gamma_{1}+\gamma_{2}+\gamma_{3}+\gamma_{4}+\gamma_{5}
$$

where

$$
\begin{aligned}
& \gamma_{1}=\int_{\eta_{B}}^{+\infty}\left[\left(\frac{\mu-r C}{r^{2}}\right)^{2}+\left(\frac{\eta_{t}}{r}\right)^{2}\right] f\left(\eta_{t}\right) d \eta_{t} \\
& \gamma_{2}=2 \int_{\eta_{B}}^{+\infty}\left(\frac{\mu-r C}{r^{3}}\right) f\left(\eta_{t}\right) d \eta_{t} \\
& \gamma_{3}=-2 \int_{\eta_{B}}^{+\infty}\left(\frac{\mu-r C}{r^{2}}\right)\left(\frac{\mu-r C+r \eta_{B}}{r^{2}}\right) x_{B}\left(\eta_{t}, \eta_{B}\right) f\left(\eta_{t}\right) d \eta_{t} \\
& \gamma_{4}=-2 \int_{\eta_{B}}^{+\infty}\left(\frac{\mu-r C+r \eta_{B}}{r^{2}}\right) \frac{\eta_{t}}{r} x_{B}\left(\eta_{t}, \eta_{B}\right) f\left(\eta_{t}\right) d \eta_{t}, \\
& \gamma_{5}=\int_{\eta_{B}}^{+\infty}\left(\frac{\mu-r C+r \eta_{B}}{r^{2}}\right)^{2} x_{B}^{2}\left(\eta_{t}, \eta_{B}\right) f\left(\eta_{t}\right) d \eta_{t} .
\end{aligned}
$$

After some calculation, we can give that

$$
\begin{aligned}
\int_{\eta_{B}}^{+\infty} \eta_{t} x_{B}\left(\eta_{t}, \eta_{B}\right) f\left(\eta_{t}\right) d \eta_{t} & =\left[\frac{\sigma \sqrt{t}}{\sqrt{2 \pi}} e^{-\frac{1}{2} j_{1}^{2}}+\left(\eta_{0}-\sqrt{\mu^{2}+2 r \sigma^{2}} t\right)\right] \Phi\left(j_{1}\right) e^{k_{2}\left(\eta_{0}-\eta_{B}\right)+r t} \\
+ & {\left[\frac{\sigma \sqrt{t}}{\sqrt{2 \pi}} e^{-\frac{1}{2} j_{2}^{2}}+\left(2 \eta_{B}-\eta_{0}-\sqrt{\mu^{2}+2 r \sigma^{2}} t\right)\right] \Phi\left(j_{2}\right) e^{k_{1}\left(\eta_{0}-\eta_{B}\right)+r t} }
\end{aligned}
$$


and

$$
\begin{aligned}
\int_{\eta_{B}}^{+\infty} x^{2}\left(\eta_{t}, \eta_{B}\right) f\left(\eta_{t}\right) d \eta_{t} & =\Phi\left(\lambda_{1}\right) e^{k_{2} \eta_{0}-2 \sqrt{\mu^{2}+2 r \sigma^{2}} t} e^{k_{2}\left(\eta_{0}-\eta_{B}\right)} \\
& +\Phi\left(\lambda_{2}\right) e^{k_{2}\left(2 \eta_{B}-\eta_{0}\right)-2 \sqrt{\mu^{2}+2 r \sigma^{2}} t} e^{k_{1}\left(\eta_{0}-\eta_{B}\right)}
\end{aligned}
$$

where

$$
\lambda_{1,2}=\frac{ \pm\left(\eta_{B}-\eta_{0}\right)+\mu t+2 \sqrt{\mu^{2}+2 r \sigma^{2}} t}{\sigma \sqrt{t}} .
$$

\section{References}

Ayyagari, M., Demirgüç-Kunt, A., and Maksimovic, V. (2014). Who creates jobs in developing countries? Small business economics, 43(1):75-99.

Beck, T. and Demirguc-Kunt, A. (2006). Small and medium-size enterprises: Access to finance as a growth constraint. Journal of Banking and Finance, 30(11):2931-2943.

Berger, A. N., Frame, W. S., and Miller, N. H. (2005). Credit scoring and the availability, price, and risk of small business credit. Journal of money, credit and banking, pages $191-222$.

Brown, J. R., Fazzari, S. M., and Petersen, B. C. (2009). Financing innovation and growth: Cash flow, external equity, and the 1990s r\&d boom. The Journal of Finance, 64(1):151185.

Canales, R. and Nanda, R. (2012). A darker side to decentralized banks: Market power and credit rationing in sme lending. Journal of Financial Economics, 105(2):353-366.

Coco, G. (2000). On the use of collateral. Journal of Economic Surveys, 14(2):191-214.

Cressy, R. (2002). Introduction: Funding gaps: A symposium. Economic Journal, pages F1-F16.

de Blasio, G., De Mitri, S., D'Ignazio, A., Russo, P. F., and Stoppani, L. (2018). Public guarantees to sme borrowing. a rdd evaluation. Journal of Banking E Finance, 96:73-86.

Goldstein, R., Ju, N., and Leland, H. (2001). An ebit-based model of dynamic capital structure. Journal of Business, 74(4 October):483-512.

Holmstrom, B. and Tirole, J. (1997). Financial intermediation, loanable funds, and the real sector. the Quarterly Journal of economics, 112(3):663-691.

Honohan, P. (2010). Partial credit guarantees: Principles and practice. Journal of Financial Stability, 6(1):1-9. 
Kuo, C.-J., Chen, C.-M., and Sung, C.-H. (2011). Evaluating guarantee fees for loans to small and medium-sized enterprises. Small Business Economics, 37(2):205-218.

Leland, H. E. (1994). Corporate debt value, bond covenants, and optimal capital structure. The journal of finance, 49(4):1213-1252.

Leland, H. E. and Toft, K. B. (1996). Optimal capital structure, endogenous bankruptcy, and the term structure of credit spreads. The Journal of Finance, 51(3):987-1019.

Leonello, A. (2018). Government guarantees and the two-way feedback between banking and sovereign debt crises. Journal of Financial Economics, 130(3):592-619.

Lin, J. Y. and Sun, X. (2006). Information, informal finance, and sme financing. Frontiers of Economics in China, 1(1):69-82.

Liu, g., Luo, P., and Yang, Z. (2016). Real option, debt maturity and equity default swaps under negotiation. Finance Research Letters, 18:278-284.

Luo, P., Wang, H., and Yang, Z. (2016). Investment and financing for smes with a partial guarantee and jump risk. European Journal of Operational Research, 249(3):1161-1168.

Myers, S. C. and Majluf, N. S. (1984). Corporate financing and investment decisions when firms have information that investors do not have. Journal of Financial Economics, $13(2): 187-221$.

OECD (2019). OECD SME and Entrepreneurship Outlook 2019.

Padilla, A. J. and Pagano, M. (1998). Collateral vs. Project Screening: A Model of Lazy Banks. CEMFI.

Pozzolo, A. F. (2004). The role of guarantees in bank lending. Temi di discussione (Economic working papers) 528, Bank of Italy, Economic Research and International Relations Area.

Riding, A. L. and Haines Jr, G. (2001). Loan guarantees: Costs of default and benefits to small firms. Journal of business venturing, 16(6):595-612.

Saito, K. and Tsuruta, D. (2018). Information asymmetry in small and medium enterprise credit guarantee schemes: evidence from japan. Applied Economics, 50(22):2469-2485.

Shan, C. and Tang, D. Y. (2019). Outsourcing bank loan screening: The economics of third-party loan guarantees. Available at SSRN 2024425.

Shreve, S. E. (2004). Stochastic calculus for finance II: Continuous-time models, volume 11. Springer Science \& Business Media.

Smith Jr, C. W. and Warner, J. B. (1979). On financial contracting: An analysis of bond covenants. Journal of financial economics, 7(2):117-161. 
Stiglitz, J. E. and Weiss, A. (1981). Credit rationing in markets with incomplete information+. American Economic Review, 71(2):393-409.

Stulz, R. and Johnson, H. (1985). An analysis of secured debt. Journal of financial Economics, 14(4):501-521.

Suryani, E. (2020). A Study on the Performance of Credit Guarantee Schemes for Micro and Small Enterprises in Indonesia. PhD thesis, NAGOYA UNIVERSITY.

Tang, X. and Yang, Z. (2017). Optimal investment and financing with macroeconomic risk and loan guarantees. Journal of Credit Risk, 13(4).

Tirole, J. (2001). Corporate governance. Econometrica, 69(1):1-35.

Vogel, R. C. and Adams, D. W. (1997). The benefits and costs of loan guarantee programs. The Financier, 4(1):22-29.

Wang, H., Yang, Z., and Zhang, H. (2015). Entrepreneurial finance with equity-for-guarantee swap and idiosyncratic risk. European Journal of Operational Research, 241(3):863-871.

Wellalage, N. H. and Fernandez, V. (2019). Innovation and sme finance: Evidence from developing countries. International Review of Financial Analysis, 66:101370.

Wilcox, J. A. and Yasuda, Y. (2008). Do government loan guarantees lower, or raise, banks' non-guaranteed lending? evidence from japanese banks. In World Bank Workshop Partial Credit Guarantees, pages 1-53.

Xiang, H. and Yang, Z. (2015). Investment timing and capital structure with loan guarantees. Finance Research Letters, 13:179-187.

Yang, Z. and Zhang, H. (2013). Optimal capital structure with an equity-for-guarantee swap. Economics Letters, 118(2):355-359.

Yoshino, N. and Taghizadeh-Hesary, F. (2018). The role of smes in asia and their difficulties in accessing finance. ABDI Working Paper Series No. 911, Asian Development Bank Institute.

Zecchini, S. and Ventura, M. (2006). Public credit guarantees and sme finance. ISAE Working Paper Series No. 73, Istituto di Studi e Analisi Economica. 